\title{
Practical Teaching Method Based on MATLAB in AC Speed Regulating System Course
}

\author{
Yang Qian \\ Department of Mechanical and Electrical Engineering \\ Xi'an University of Architecture and Technology \\ Xi'an, China \\ yangqian0516@126.com
}

\author{
Gao Jinzhu \\ School of Engineering and Computer Science \\ University of The Pacific \\ California, USA \\ jgao@pacific.edu
}

\begin{abstract}
Because an AC speed regulating system is abstract and complex, the study on practical teaching method based on MATLAB software is quite necessary in the AC speed regulating system course at our university. The permanent magnet synchronous motor (PMSM) vector control system is taken as an example to explain in details the practical teaching method based on MATLAB. The course content is divided into several knowledge modules based on speed regulation methods. The concept of subsystem in Simulink is introduced. Each type of speed regulating systems can be divided into several subsystems according to its functions. The control principle, system constitution and design method of each AC speed regulation system is explained by different function subsystems. The instructor vividly demonstrates the control system simulation model of AC speed regulation systems in class, and the students establish and modify the existing simulation model by themselves on the computers under the guidance of the instructor. In this way, the students' practical ability and teaching quality of specialized courses can be improved greatly.
\end{abstract}

Keywords-AC speed regulation system; practical teaching method; subsystem; MATLAB/Simulink;

\section{INTRODUCTION}

The full name of MATLAB is Laboratory Matrix, developed by MathWorks. MATLAB is mainly used for scientific computing, data analysis and visualization and interactive programming. The MATLAB family has three members, namely, MATLAB, MATLAB Toolboxes and Simulink. Simulink, a visual simulation tool in MATLAB and a software package for dynamic system modeling, simulation and analysis, is widely used in modeling and simulation of linear systems, nonlinear systems, digital control and digital signal processing. The power system toolbox of Simulink is a module library dedicated to the RLC circuit, power electronic circuit, motor drive control and power system simulation. This module library contains a variety of AC / DC power supply, a large number of electrical components and electrical measuring instruments and analysis tools, etc. The operations and faults of the power system in various states can be simulated by using these modules ${ }^{[1]}$.

With the rapid development of microelectronics, power electronics, modern control theory and computer application technology, the study of AC speed regulation technology has become a popular field. In particular, the advanced speed control methods, such as direct torque control, vector control and synchronous motor variable frequency speed regulation technology have been applied to AC speed regulation systems. Replacing DC speed regulation with AC speed regulation is an inevitable trend. With the advantages of fast response, high accuracy and energy saving, AC speed regulation systems are widely used in industrial production and high performance driving fields.

The AC speed regulating system course covers the subjects of electrical machinery, power electronics, modern control theory and computer science ${ }^{[2]}$. Because the AC speed regulating system is abstract and complex, it is difficult for students to completely understand lectures. The challenges for the instructor lie in the following questions: How to help the students deeply understand the control principle, system structure and design method of an AC speed regulation system? How to motivate the class and enhance the students' practical ability? How to improve the teaching quality of the AC speed regulation system course?

\section{TEACHING PURPOSES}

AC Speed Regulation System is an important professional course in electrical engineering and automation major, and it is a basis for further learning motion control system and electrical energy saving technology. Taking into account the current teaching environment and the professional knowledge of the students in our university, the main goal of the teaching method reform is to motivate the class and improve the students' practical ability.

\section{PRACTICAL TEACHING METHOD BASED ON MATLAB}

The AC Speed Regulation System course needs to cover two major topics: asynchronous motor speed regulation technology and synchronous motor speed regulation technology. The teaching objectives are to make the students understand the basic principles of vector control, direct torque control and variable frequency speed regulation method and to design AC speed regulation systems for two types of motors with these control methods. The teaching content can be divided into several knowledge modules based on speed regulation methods. The important knowledge points should be 
strengthened, and the forefront of AC speed regulation technology should be highlighted in the course teaching.

\section{A. INTRODUCTION OF AC SPEED REGULATION \\ TECHNOLOGY}

In this module, the DC speed control systems, their applications and disadvantages are first introduced; Then, AC speed regulation systems, their applications and advantages compared with DC speed regulation system are explained in details; Finally, the development of modern control theory and power electronic which are closely related to AC speed regulation system are taught separately ${ }^{[3]}$. The control system simulation models based on Simulink can vividly demonstrate the system constitution and performance of AC speed regulation systems. The students' learning interest is stimulated, and the further study of the following theory modules becomes reasonable. AC speed regulation system simulation examples include:

1) Airship electric propulsion system.

2) High-speed aircraft electro hydraulic servo system

3) Multi-electric aircraft electrohydrostatic actuators

4) Electric vehicle drive system

5) Air condition system

6) Wind power generator

7) Locomotive traction system

Although this module is not a part of the exam, it is quite important for students to completely study the control principle, system structure and design method of AC speed regulation system.

\section{B. Practical Teaching Method Based on MATLAB}

There are many speed control methods for AC speed regulation systems. Therefore, it is necessary to apply appropriate teaching strategies according to the knowledge structure of electrical engineering and automation major. PMSM vector control system theory module teaching is taken as an example to explain the practical teaching method based on MATLAB. The teaching materials for this theory module cover the control system constitutions and design method of the PMSM vector control system. The main knowledge points are: (1) the rotor structure, advantages and mathematical model of permanent magnet synchronous motor; (2) vector control principle, coordinate transformation and PID controller; (3) current hysteresis PWM method ${ }^{[4]}$. The concept of subsystem in Simulink is introduced, and the vector control system can be divided into 5 subsystems. The PMSM vector control system structure based on subsystems is shown in Figure1.

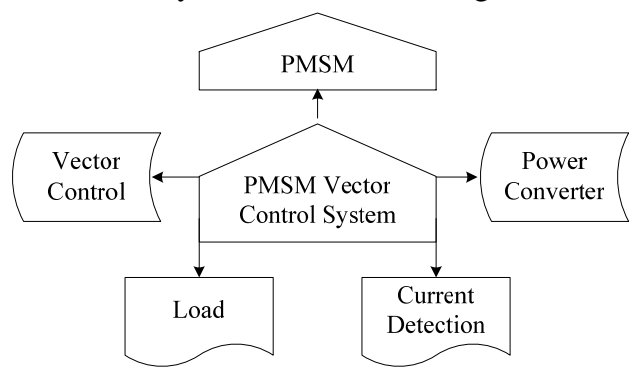

Fig. 1. PMSM vector control system structure based on subsystems
Firstly, the control principle, system constitutions and design method of AC speed regulation system are explained through different function subsystems. Secondly, the basic simulation model of the PMSM vector control system will be dynamically demonstrated in MATLAB, as shown in Figure 2. This part is what attracts the students most. Thirdly, the design method of vector control system is explained in detail by subsystems models according to above knowledge points. By running real-time simulation model and analysis of control system under different initial conditions, load torque and control parameters, students can directly observe performance changes of the control system under the condition of external interference, and deepen the understanding of the theoretical knowledge. Then, students establish the simulation model of vector control system all by themselves on their computers, and observe the output results for the given simulation conditions under the guidance of the instructor. Finally, based on the instructor's feedbacks, the students rebuild the control system model and summarize the analysis of the experiment results on paper. The teacher will then give the final evaluation.

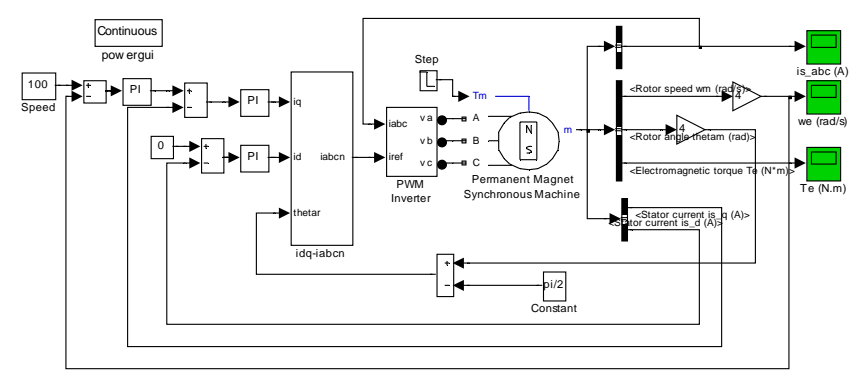

Fig. 2. Simulation model of PMSM vector control system

In order to finish the assignment, the students have to read the relevant papers in the library. The students need to know the latest achievements of AC speed regulation technology and broaden their horizons. In this way, students not only improve their ability to study professional literature but also become more motivated to take professional courses.

\section{CONCLUSIN}

The permanent magnet synchronous motor vector control system is taken as an example to explain in detail the practical teaching method based on MATLAB. Firstly, the course content can be divided into several knowledge modules according to speed regulation methods. The concept of subsystems in Simulink is introduced. The control principle, system constitution and design method of AC speed regulation system are taught through different function subsystems. The instructor vividly demonstrates the simulation models of AC speed regulation systems in class, and the students establish and modify the existing simulation models all by themselves on their computers under the guidance of the teacher. In this way, it can improve both the students' practical ability and teaching quality of specialized courses. 


\section{REFERENCES}

[1] Zhang Zhiyong, Yang Zuying, MATLAB Examples. Beihang University Press, 2015.

[2] Zhang Yongjun, Pan Yuedou, Li Huade, Modern AC Speed Regulation System. China Machine Press, 2014.

[3] Liu Baolian, "Study on the teaching method of AC speed regulation system course,” Jounal of Science \& Techology Vision, No.18, pp:98-99, 2012.

[4] Yang Qian, Liu Weiguo and Luo Guangzhao, "Study on PWM Technology of PMSM Control System Based on dSPACE," Small and Special Electrical Machines, No.6, pp: 37-40, 2010. 